\title{
Using Cartographic and Archival Material to Approach Local History: an Educational Workshop about Lambrakis Case in Thessaloniki City of the '60s.
}

\author{
Nopi Ploutoglou $^{\text {a, *, Sofia Pavlidou }}{ }^{\text {a }}$, Maria Pazarli a ${ }^{\text {a }}$ Elpis Daniil ${ }^{\text {a }}$ \\ a GSA-HAM-Cartographic Heritage Archives, ploutoglou@maplibrary.gr,pavlidous@gmail.com,pazarli@maplibrary.gr, \\ daniil@maplibrary.gr \\ * Corresponding author
}

Keywords: Cartographic Heritage, Archives, Local History, Urban Maps, Educational Workshops, Digital Humanities, Grigoris Lambrakis

\begin{abstract}
:
A main concern of Cartographic Heritage Archives as a department of General State Archives of Greece-Historical Archives of Macedonia, in the frame of management and diffusion of cartographic heritage, is to ensure the distinctive role of maps in Archives and at the same time to propose them, as snapshots of the past in order to connect archival material and human activity with geospace over time.

Grigoris Lambrakis is a charismatic personality of modern Greek political history in the '60s: doctor, Lecturer of the School of Medicine at the University of Athens and member of the Greek Parliament, he was also known as champion athlete, as member of the Greek resistance during WWII and as antiwar activist, with participation in international pacifist meetings, demonstrations and to the First Pacifist Rally from Marathon to Athens. His assassination in Thessaloniki on May 22nd, 1963, after a speech at an anti-war event and the trial that followed later, led to a major political crisis and initiated an enormous popular reaction in Greece and worldwide. Grigoris Lambrakis, a symbol of peace and democracy, represents also the struggle against political repression and continues to excite and inspire. His life and death inspired the creation of major art works (literature, poetry, painting, songs, cinema and documentaries) and the case became widely known in Greece and worldwide till today.
\end{abstract}

The judicial archives of Lambrakis case are a valuable part of Historical Archives of Macedonia collections. Having in mind the timeless values that Lambrakis defended, a workshop was prepared for pupils, students and adults, as an example of good practice that aims to provide primary sources opening a direct window on past events to better understand the facts and the geography of Lambrakis case. At the same time, to highlight the possibilities of the combined use of archival documents and cartographic material in preserving memory, linking places of the past with the places we live in today. During the research and processing of this archive, we realized that in order to follow and fully understand from the archival material, the line of events that took place in Thessaloniki in 1963 it was necessary to "reconstruct" the city of the '60s. To achieve this, the judicial archive was used in conjunction with maps of that time, photographs, newspapers etc. Selected archival material was also used for the presentation and tasks, always following the rules regarding the protection of personal data.

Main aims of this project are: Making the archival material known and encourage access, create archive users and supporters, provide the educational process with primary sources, emphasize to the important role of archives as historical sources, connect with the past in an active and creative way, interpret and understand the present and help the participants to shape opinions and attitudes. In addition to the historical thinking skills developed, the use of maps encourages critical and spatial thinking, cultivate cartographic skills (recognition, localization, comparison, analysis, etc.) and connect the archival material with geospace and human activity over time. Understanding geographical information expands the perception of the city and inspires problem solving, incorporates visual learning and quantitative skills. Historical maps represent views of their time, hold information for the natural and the anthropogenic characteristics of the community and help us to visualize areas, recognize similarities and discover the changes which have taken place over time.

The project was prepared in order to be implemented as an educational workshop. Nevertheless, because of the pandemic of covid-19, it was converted and implemented online. In this paper we present the activities, exercises and worksheets that have been prepared, for the purposes of the workshop, the results and conclusions from this combined use of cartographic and archival material, as well as the web application of the program and the tools used. 